УДК 340.1

DOI 10.52575/2712-746X-2021-46-4-757-766

\title{
Природа и сущность правоприменительного юридического процесса: постановка проблемы
}

\author{
Хабиева 3.Д., Ярычев Н.У. \\ Чеченский государственный университет имени А.А. Кадырова, \\ Россия, 364093, г. Грозный, ул. А. Шерипова, 32 \\ E-mail: belvp46@gmail.com
}

\begin{abstract}
Аннотация. Авторы в порядке постановки проблемы излагают точку зрения о природе и сущности не получившего в правовой науке должного освоения правоприменительного юридического процесса. Рассмотрены теоретические основы изучаемого предмета: правореализация и правоприменение, включая правоприменительную деятельность и правоприменительный процесс, затем - ключевые положения теории юридического процесса и его видов. Отмечены разные мнения относительно сущности, содержания, видов и т.д. юридического процесса, что объясняется наличием в правовой науке узкого и широкого подходов к определению его понятия. В своем большинстве ученые поддерживают идею о широком понимании юридического процесса как комплексной системы правовых форм государственной деятельности, распространяя его и на другие сферы. При классификации юридического процесса выделен правоприменительный процесс, включающий в себя юрисдикционный и другие (позитивного свойства) процессы. С авторской позиции правоприменительный юридический процесс - это только юрисдикционный процесс, осуществляемый всеми формами судопроизводства. Следовательно, природа и сущность правоприменительного юридического процесса проявляется в ходе и по результатам конституционного, гражданского, арбитражного, административного и уголовного судопроизводства и заключается в судебном рассмотрении и разрешении в процессуальной форме юридических дел (правовых споров) в целях получения юридического, социально-значимого результата.
\end{abstract}

Ключевые слова: правореализация, правоприменение, правоприменительный процесс, юридический процесс, правообразовательный процесс, правореализационный процесс, сущность, правоприменительный юридический процесс.

Для цитирования: Хабиева З.Д., Ярычев Н.У. 2022. Природа и сущность правоприменительного юридического процесса: постановка проблемы. NOMOTHETIKA: Философия. Социология. Право, 46 (4): 757-766. DOI: 10.52575/2712-746X-2021-46-4-757-766

\section{The Nature and Essence of the Law Enforcement Legal Process: Problem Statement}

\author{
Zaira D. Khabieva, Nasrudi U. Yarychev \\ Kadyrov Chechen State University, \\ 32 A. Sheripova St, Grozny 364093, Russian Federation \\ E-mail: belvp46@gmail.com
}

\begin{abstract}
The authors, in order to pose the problem, state their point of view about the nature and essence of the law enforcement legal process that has not received proper development in legal science. The theoretical foundations of the subject under study are considered: legal realization and law enforcement, including law enforcement activities and law enforcement process, then the key provisions of the theory of
\end{abstract}


the legal process and its types. Research in this vein required starting it with certain aspects of legal realization, which includes its special form - law enforcement, the value of which lies in ensuring and obtaining appropriate results. There are different opinions on the essence, content, types, etc. of the legal process, which is explained by the presence in legal science of narrow and broad approaches to the definition of its concept. For the most part, scientists support the idea of a broad understanding of the legal process as a complex system of legal forms of state activity, extending it to other areas. The signs of the legal process (legal activity, special subject composition, procedural nature, relevance to the resolution of legal cases, etc.) indicate its essence, which should be understood as a complex legal means by which procedural activities for the consideration and resolution of legal cases (legal disputes) are regulated. From the author's point of view, the law enforcement legal process is only a jurisdictional process carried out by all forms of legal proceedings. Consequently, the nature and essence of the law enforcement legal process manifests itself during and according to the results of constitutional, civil, arbitration, administrative and criminal proceedings and consists in judicial review and resolution in procedural form of legal cases (legal disputes) in order to obtain a legal, socially significant result.

Keywords: legal realization, law enforcement, law enforcement process, legal process, legal education process, legal realization process, essence, law enforcement legal process

For citation: Khabieva Z.D., Yarychev N.U. 2022. The Nature and Essence of the Law Enforcement Legal Process: Problem Statement. NOMOTHETIKE: Philosophy. Sociology. Law, 46(4): 757-766 (in Russian). DOI: 10.52575/2712-746X-2021-46-4-757-766

\section{Введение}

Предваряя рассмотрение проблемы, прежде всего отметим, что вопросу реализации права, одной из форм которой является правоприменение (и правоприменительный процесс, правоприменительная деятельность соответственно), в правовой науке уделено большое внимание, так как именно благодаря правореализационному процессу нормы права в широком их понимании (как правовые установления, правовые средства, правовые формы, способы, средства и т.д.) воплощаются, претворяются в реальную жизнь, социальное бытие и становятся основным средством правового регулирования общественных отношений.

Реализация нормы права представляет собой процесс превращения идеальных юридических моделей, отражающих нужные для общества состояния, в практическую реальность, в действующую систему общественных отношений.

Характерно, что реализацию права можно рассматривать и как своеобразный процесс, и как его конечный результат. Вместе с тем, нельзя не заметить, что вопросы относительно реализации права, классификации форм этой реализации и т.д. не «закрыты», в этом плане продолжаются дискуссии.

Для настоящей работы полагаем достаточным и методологически обоснованным ограничиться изложением сущности форм правореализации и юридического процесса (его видов) как основе предмета настоящего исследования - правоприменительного юридического процесса.

В теории права устоявшимся является подход, согласно которому выделяются такие формы реализации права, как соблюдение, исполнение, использование и применение права. Применение права является особой формой реализации права. Применение права это комплекс мыслительных и фактических, организационных и юридических операций (действий) субъектов правоприменения в целях обеспечения процесса реализации правовых предписаний, завершающийся решением компетентного органа по конкретному юридическому делу.

Н.Н. Вопленко отмечает: «В отличие от соблюдения, исполнения и использования результаты правоприменения характеризуются повышенной степенью социальной значимости. Это определяется особой важностью тех общественных отношений, которые регу- 
лируются правоприменительной деятельностью. Государство не может и не должно ставить развитие определенных сторон социальной жизни в зависимость от личного произвола отдельных лиц, случайностей и иных факторов неуправляемости, а, наоборот, обязано программировать достижение «эффекта гарантированного результата». Ценность правоприменения как раз и состоит в его способности максимально обеспечивать социально ценные результаты правореализации» [Вопленко, 2009, с. 400].

В контексте настоящей работы для уяснения природы и сущности правоприменительного юридического процесса, наряду с правоприменением, важным становится рассмотрение отдельных вопросов и юридического процесса (его видов).

\section{Юридический процесс и его виды}

Обратимся к теории юридического процесса, состояние которой А.А. Павлушина охарактеризовала следующим образом: «Теория юридического процесса при всей своей разнородности представляет в рамках российской общей теории права самостоятельное, изолированное вплоть до самого последнего времени образование, практическая значимость которого и до настоящего времени не оценена; в практике правового регулирования она фактически не используется, а теоретическую исследованность процесса ни в коем случае нельзя признать состоявшейся, законченной, утвердившейся в науке» [Павлушина, 2005, c. 9].

Несмотря на то, что прошло уже определенное время, утверждение А.А. Павлушиной применимо и к современной научной мысли о теории юридического процесса, включающей в себя вопросы сущности, содержания, видовой классификации, формы и т.д.

В свое время видный ученый-теоретик профессор В.М. Горшенев о значении юридического процесса высказался так: «Основное назначение этой категории состоит в том, чтобы всемерно способствовать в методологическом плане настойчивому проведению требования по преодолению идеи процессуального нигилизма в юридической науке и во всех сферах юридической практики. Кроме того, введение понятия юридический процесс позволяет представить его как специфический комплекс, устойчивое структурное образование, заключающее в себе органическое сочетание общих свойств всего целого и специфических особенностей каждого структурного подразделения» [Горшенев, 1979, с. 3].

Прошли годы, но дискуссионность в определении понятия юридического процесса остается. К примеру, до настоящего времени нет (не выработано) даже унифицированного понятия юридического процесса. И главным моментом такой ситуации следует признать наличие в правовой науке так называемых узкого и широкого подходов к его пониманию и дефиниции.

Сторонники узкого понимания юридического процесса когда-то поставили знак равенства между данным понятием и судебным правом; их основной довод заключался в так называемом традиционном понимании термина «процесс», к которому отнесены были гражданский и уголовный процессы [Проблемы судебного права, 1983, с. 17]. Четко и недвусмысленно в этом плане высказался, к примеру, П.Ф. Елисейкин: «Мы не разделяем широкое понимание процесса, охватывающее все организационные формы правоприменительной деятельности (а, по мнению отдельных авторов, все формы реализации права). Полагаем, что юридический процесс есть лишь правоохранительная деятельность компетентных органов государства - его юрисдикционных органов» [Елисейин, 1979, с. 37].

Видный теоретик права С.С. Алексеев также считал, что «расширительное толкование понятия "процесс" "обескровливает, выхолащивает" это "богатое и содержательное понятие", которое может быть воспринято лишь в специальном юридическом смысле, сложившемся исторически, то есть применительно к уголовному и гражданском судопроизводствам» [Алексеев, 1971, с. 122]. 
Однако со временен ситуация изменилась, и анализ научных взглядов свидетельствует о том, что на сегодня превалирующим является «широкое» понимание юридического процесса, то есть получила признание следующая точка зрения В.М. Горшенева и его сторонников о распространимости юридического процесса и на другие сферы (не только судебной деятельности в так называемых классических видах судопроизводства) и правовые формы государственной деятельности: «Юридический процесс - это комплексная система органически взаимосвязанных правовых форм деятельности уполномоченных органов государства, должностных лиц, а также заинтересованных в разрешении различных юридических дел иных субъектов права, которая: а) выражается в совершении операций с нормами права в связи с разрешением определенных юридических дел; б) осуществляется уполномоченными органами государства и должностными лицами в пользу заинтересованных субъектов права; в) закрепляется в соответствующих правовых актах - официальных документах; г) регулируется процедурно-процессуальными нормами, д) обеспечивается соответствующими способами юридической техники» [Горшенев, 1985, с. 8].

При этом заметим, важно то, что широкое понимание юридического процесса было показано в увязке с правовым регулированием общественных отношений: «Укажем также, что всестороннее исследование проблем юридического процесса, возможность его широкого понимания в совокупности представляют собой скрытый резерв поиска путей и методов дальнейшего повышения эффективности правового регулирования» [Горшенев, 1985, c. 14].

Изложенная позиция воспринята многими современными авторами. Отметим точки зрения отдельных из них: «Юридический процесс должен рассматриваться как последовательная смена каких-либо правовых явлений, состояний, возникающих в жизни общества и вызываемых юридически значимыми действиями, совершаемыми носителями публичной власти, гражданами и юридическими лицами. Такое движение юридических явлений, переход из одного юридического состояния в другое происходит в ходе правового регулирования государством общественных отношений» [Гадыльшниа, 2003, с. 119].

В другом случае под юридическим процессом понимается «комплексная система осуществления всех видов юридической деятельности, осуществляемых в процессуальной форме, направленных на разрешение юридических дел в целях удовлетворения интересов субъектов права» [Беляев, Сорокина, 2011, с. 38].

По мысли Е.Г. Лукьяновой, многообразие подходов к определению юридического процесса сводится к пяти основным направлениям, существующим в современной юридической науке: «...а) как юрисдикционную и иную охранительную деятельность органов правосудия, направленную на разрешение споров о праве и осуществление правового принуждения в рамках правосудия и в связи с ним; б) как юрисдикционную и иную охранительную деятельность уполномоченных органов государства и иных субъектов; в) как всю правоприменительную и правотворческую деятельность компетентных органов («организационные общественные отношения», складывающиеся в процессе правотворчества и правоприменения); г) как процесс реализации материально-правовых норм безотносительно к формам такой реализации (в данном случае трудно определить границу между материальными и процессуальными явлениями в праве); д) как любая юридическая деятельность государственных (и муниципальных. - Aвт.) органов (правотворческая, правоприменительная, контрольная, учредительная, распорядительная)» [Лукьянова, 2003, с. 41].

С нашей позиции, правовая категория «юридический процесс» призвана регулировать не только осуществление правосудия, но и другие позитивные процессы реализации права; юридический процесс, кроме правоприменительной деятельности, имеет отношение и к правотворчеству, деятельности, также подчиняющейся определенным процессуальным правилам (форме).

Уместно отметить, что широкое понимание юридического процесса разделяется также представителями отраслевых юридических наук. 
Относительно признаков юридического процесса скажем, что это, прежде всего, юридическая деятельность как в юрисдикционных, так и других, позитивного свойства, процессах. К другим признакам (особенностям, чертам и т.д.) юридического процесса следует отнести особый субъектный состав, включающий в себя как субъектов, так и других участников процесса. Безусловно, юридический процесс - это комплексная (по В.М. Горшеневу - полиструктурная) система, отличающаяся системностью. Кроме того, юридический процесс всегда осуществляется в процессуальной форме (каждой разновидности юридического процесса присуща, свойственна «своя» процессуальная форма). Конечно же, юридический процесс - это всегда деятельность, причем, юридическая и процессуальная.

В то же время Е.Г. Лукьянова считает, что процесс - это средство упорядочения и организации общественных отношений [2003, с. 79]. И такое суждение возражений не вызывает, поскольку считаем возможным юридический процесс отнести к средствам процессуально-правового регулирования указанных отношений.

В число признаков юридического процесса входят также рассмотрение и разрешение юридических дел (правовых споров), то есть наличие автономного объекта, по результатам которого принимаются (выносятся) юридически значимые процессуальные акты документы. К другим признакам юридического процесса ученые относят соответствие правовым и процессуально-правовым принципам, рациональность и некоторые другие.

В своей совокупности признаки юридического процесса выражает его природу и сущность. Полагаем, что под сущностью юридического процесса следует понимать комплексное правовое средство, при помощи которого регламентируется процессуальная деятельность по рассмотрению и разрешению юридических дел (правовых споров) с целью получения результата правового характера.

Все изложенное позволяет перейти к видовой классификации юридического процесса - вопросу, по которому нет устоявшегося подхода и высказываются различные точки зрения. По нашему мнению, в этом нет ничего удивительного (нелогичного), если принимать во внимание деление юридического процесса на его только широкое либо узкое понимание, тогда как и других оснований (критериев) для его видовой конфигурации достаточно.

Думается, что наиболее приемлемым и отвечающим природе и сущностносодержательным реалиям классификации юридического процесса будет подход, согласно которому он должен быть классифицирован прежде всего на такие типы, как правообразовательный и правореализационный. В первый из них включим правотворчество (правотворческий процесс) - это специфическая деятельность управомоченных субъектов по подготовке, утверждению и официальному оглашению нормативно-правовых актов. Конечным результатом такой деятельности становится соответствующее нормативноправовое предписание (нормативный акт).

Правоприменительный процесс относится к правореализационному типу и он (по B.M. Горшеневу) занимает доминирующее место в системе юридического процесса [Горшенев, 1979, с. 9].

Так, по мнению В.В. Лазарева, «правовое регулирование процесса применения права происходит по следующим основным направлениям: 1) в нормативных актах указываются необходимость и пределы правоприменения; 2) устанавливаются субъекты правоприменения и круг лиц, участвующих в деле (также порядок их привлечения к процессу); 3) в той или иной мере определяется порядок совершения правоприменительных действий; 4) закрепляется правовой режим доказательств по делу, предпринятых по нему расходов и прочее; 5) до определенной степени (в общей форме) предопределяется результат правоприменения; 6) устанавливаются возможные случаи пересмотра правоприменительных решений; 7) в нормах права предусматривается юридическая ответственность субъектов правоприменения и ее пределы» [Лазарев, 1975, с. 168].

В свою очередь, правоприменительный процесс подразделяется на юрисдикционный юридический процесс (с нашей позиции, он присущ только судопроизводству) и на 
неюрисдикционные (их еще называют позитивными) процессами; главным отличием между ними является наличие (отсутствие) правового спора. По этому поводу Н.Н. Вопленко высказывается так: «Юрисдикционный способ применения права является наиболее характерным и традиционным выражением правоприменительной деятельности путем рассмотрения судебными органами споров о праве или решения вопроса назначения наказания виновному лицу» [Вопленко, 2009, с. 409].

В зависимости от категории разрешаемого спора и от судебного органа, осуществляющего его разрешение, юрисдикционные процессы - это гражданский, арбитражный, уголовный, конституционный и административный процессы.

В связи со сказанным, следует заметить определенную сложность в понимании административного процесса, о котором в науке административного права уже давно идут непрекращающиеся дискуссии и который «расчленен» структурно на управленческий, процедурный и правоприменительный административный процесс. Как представляется, о юрисдикционном административном процессе следует вести речь только как о судебной деятельности соответствующего порядка.

Классифицируя юридический процесс, следует назвать и учредительный юридический процесс, который стоит как бы особняком в силу своей специфики и фактически не включается ни в правообразование, ни в правореализацию.

О нем пишет В.М. Горшенев, как о «специфической деятельности уполномоченных органов государства, должностных лиц и общественных организаций по реализации норм материального права, устанавливающих их правомочия по формированию, ликвидации или преобразованию органов государства, должностных лиц и иных управляющих субъектов. Данная деятельность выражается главным образом в совершении действий по подготовке условий организации, проведению выборов или назначению управляющих субъектов и утверждению соответствующих учредительных результатов. < ..> В учредительном процессе легко обнаруживаются все элементы процессуальной формы, в которых можно проследить специфические черты и особенности каждой из разновидностей. Причем обращает на себя внимание такое обстоятельство, что юридическая характеристика производств и стадий некоторых видов учредительного процесса нашло свое законодательное закрепление» [Горшенев, 1979, с. 5].

Указанному процессу также посвящена кандидатская диссертация Л.Н. Гиниятуллиной, по мнению которой «учредительный юридический процесс представляет собой сложное материально-процессуальное образование, базирующееся на взаимодействии материальных и процессуальных правовых норм и соответствующих им правоотношений, являющихся результатом правового регулирования, складывающихся в определенной последовательности, направленных на формирование, ликвидацию или преобразование органов, учреждений, должностных лиц и иных субъектов права и выступающих в качестве особого нормативного порядка осуществления властной управленческой деятельности по осуществлению (реализации) соответствующих правовых норм» [Гиниятуллина, 2007, с. 36].

Таким образом, исходя из природы и сущности правопримения, а также основных аспектов теории юридического процесса и его видовой конфигурации, мы вплотную подошли к возможности дальнейшего исследования по заявленной теме о природе и сущности правоприменительного юридического (именно) процесса.

\section{Правоприменительный юридический процесс: доктринальное осмысление понятия}

Как уже отмечалось, правоприменительный процесс занимает главное (по В.М. Горшеневу - доминирующее) место в системе юридического процесса, и, следовательно, является его видом. Однако исторически (и фактически) сложилась такая практика, при которой в подавляющем большинстве случаев в названии (употреблении, исполь- 
зовании и т.д.) такой правовой категории, как правоприменительный юридический процесс слово «юридический» как бы опускается, не называется; возможно и потому, что конструкция «правоприменительный процесс» более удобна в употреблении (произношении), хотя, полагаем, имеется заметная разница в сущности и содержании правоприменительного и правоприменительного юридического процессов.

Так, еще у истоков научной разработки теории юридического процесса он классифицировался как учредительный, правотворческий и правоприменительный процессы. В дальнейшем как теоретики, так и представители отраслевых наук в своих работах в основном употребляли понятие «правоприменительный процесс», исключая его юридический характер.

Аналогичная картина наблюдается и в современной науке - превалирующим остается использование словосочетания «правоприменительный процесс». И только в отдельных трудах можно встретить такое название, как правоприменительный юридический процесс. К примеру, в статье о роли юридического процесса в правоприменительной деятельности И.С. Куксин пишет: «Существует общетеоретическое понятие юридического процесса, одним из видов которого является правоприменительный юридический процесс. Полагаем, что правоприменение и правоприменительный юридический процесс - это синонимичные понятия, поскольку правоприменение, как и правоприменительный юридический процесс, проходит ряд строго очерченных этапов, стадий. Правоприменение достигает цели исключительно в рамках правоприменительного юридического процесса. Правоприменительный юридический процесс - есть легальная форма правоприменения. Следовательно, правоприменительный юридический процесс - это регламентируемая нормами права целенаправленная, динамическая деятельность органов государственной власти, носящая комплексный характер и представляющая собой совокупность последовательных взаимосвязанных правовых процедур, действий, возникающих по поводу принудительного восстановления правопорядка» [Куксин, 2008, с. 104].

Как следует из такого подхода, автор ставит знак равенства между понятиями правоприменительного процесса и правоприменительного юридического процесса (правоприменения), считает их идентичными, хотя, повторимся, это не так.

Прежде, чем высказать свою позицию по данному вопросу, назовем еще одну статью, в которой также речь идет о правоприменительном юридическом процессе, причем в прямой постановке вопроса, что следует из самого названия статьи. Ее авторы Л.Д. Чулюкин и В.В. Гурьянова подчеркивают, что «проблема понимания сущности правоприменительного юридического процесса представляет значительный интерес для юридической науки и практики, ее исследование раскрывает малоизученные стороны правоприменительной деятельности. В настоящее время проблема правоприменительного процесса приобрела особую актуальность в связи с реформированием процессуального законодательства, принятием Кодекса административного судопроизводства РФ. Исследование данной проблемы необходимо в целях выявления пробелов законодательного регулирования правоприменительного юридического процесса, совершенствования механизма преодоления правоприменительных ошибок и повышения эффективности и качества современной практики применения права» [Чулюкин, Гурьянова, 2018, с. 125].

По существу этого мнения возражений нет, но обратим внимание, что эти авторы, кроме упоминания (в этой цитате и названии статьи), фактически исследуют не правоприменительный юридический процесс (как заявлено), а - правоприменительный процесс (именно); ими не показано различие указанных понятий.

Вместе с тем в контексте нашего исследовании важно обратить внимание на такую мысль данных авторов: «В зависимости от компетенций участников правоприменительно- 
го процесса следует выделять юрисдикционный и неюрисдикционный процесс. В рамках юрисдикционного правоприменительного процесса соответствующие субъекты разрешают юридические споры и дела о правонарушениях» [Чулюкин, Гурьянова, 2018, с. 127].

С нашей точки зрения, именно юрисдикционный и неюрисдикционный характер деятельности субъектов правоприменительного процесса выступает основанием для различения правоприменительного процесса вообще и его разновидности - правоприменительного юридического процесса. Считаем, что в том случае, когда осуществляется юрисдикционная деятельность, необходимо вести речь о правоприменительном юридическом процессе. В иных случаях правоприменения правомерно говорить только о правоприменительном процессе (процессах) позитивного характера (лицензионный, избирательный, бюджетный и т.д.).

Таким образом, мы фактически обращаемся к так называемому узкому пониманию юридического процесса и ставим знак равенства между судопроизводством в его конституционных формах (конституционное, гражданское, арбитражное, административное и уголовное) и правоприменительным юридическим процессом.

В результате гражданский, арбитражный, уголовный, административный и конституционный процессы - это правоприменительные юридические процессы, сущность которых составляет юридическая деятельность по рассмотрению и разрешению юридических дел и правовых споров в соответствующей процессуальной форме.

Такова наша позиция в вопросе (и в порядке постановки научной проблемы) о природе и сущности правоприменительного юридического процесса.

\section{Заключение}

В настоящей статье в порядке постановки научной проблемы представлена авторская позиция относительно природы и сущности правоприменительного юридического процесса как разновидности последнего. Показано, что одной из важнейших форм правореализации является правоприменение (правоприменительная деятельность, правоприменительный процесс). Выявлены особенности правоприменения, осуществляемого в процессуальной форме управомоченными субъектами, направленного на рассмотрение и разрешение юридических дел (правовых споров) в целях достижения поставленных целей и получения соответствующих результатов, выраженных в правоприменительных актах.

Отмечено, что в современной юридической науке дискуссионными являются вопросы относительно понятия и содержания юридического процесса и его процессуальной формы, видовой конфигурации данного процесса, их природы, сущности и роли в процессуально-правовом регулировании общественных отношений.

Рассмотрение научных подходов к понятию юридического процесса и его видов дало возможность определиться с понятием юридического процесса как комплексной системы процессуального характера и его природой и сущностью. Выделены такие его типы, как правообразовательный и правореализационный процессы. Последний включает в себя правоприменительный процесс, подразделяемый на юрисдикционный и другие, позитивные процессы.

Все изложенное дает возможность высказать авторскую точку зрения, согласно которой правоприменительный юридический процесс - это только юрисдикционный процесс, осуществляемый во всех формах судопроизводства.

Следовательно, природа и сущность правоприменительного юридического процесса проявляется в ходе и по результатам только судопроизводства - конституционного, гражданского, арбитражного, административного и уголовного - и заключается в судеб- 
ном рассмотрении и разрешении в процессуальной форме юридических дел (правовых споров) в целях получения юридического, социально-значимого результата.

\section{Список литературы}

1. Вопленко Н.Н. 2009. Очерки общей теории права. Волгоград, Издательство ВолГУ, 898 с.

2. Павлушина А.А. 2005. Теория юридического процесса: итоги, проблемы, перспективы развития. Под ред. В.М. Ведяхина. Самара, Самарская государственная экономическая академия, $480 \mathrm{c}$.

3. Горшенев В.М. 1979. О разновидностях юридического процесса. В кн.: Актуальные проблемы юридического процесса в общенародном государстве: межвузовский тематический сборник. Под ред. В.М. Горшенева. Ярославль, Ярославский государственный университет: 3-10.

4. Полянский Н.Н., Строгович М.С., Савицкий В.М., Мельников А.А. 1983. Проблемы судебного права. Под ред. В. М. Савицкого. Москва, Наука, 223 с.

5. Алексеев С.С. 1971. Социальная ценность права в советском обществе. Москва, Юрид. лит., $221 \mathrm{c.}$

6. Бенедик И.В., Горшенев $\quad$ В.М., Крупин $\quad$ В.Г., Мельников $\quad$ Ю.И., Олейников С.Н., Погребной И.М., Шахов И.Б. 1985. Теория юридического процесса. Под общ. ред. В.М. Горшенева. Харьков, Вища шк., Изд-во при Харьк. Ун-те, 192 с.

7. Гадыльшина 3.И. 2003. О некоторых актуальных проблемах административнопроцессуального права. В кн.: Актуальные проблемы юридической науки и образования на современном этапе. Материалы научно-практической конференции, посвященной 50-летию восстановления юридического факультета в Казанском государственном университете (Казань, 30-31 октября 2002 г.). Казань, Изд-во Казан. ун-та: 118-124.

8. Беляев В.П., Сорокина В.В. 2011. Процессуальная форма юридической деятельности: вопросы теории и практики. Москва, Юрлитинформ, $144 \mathrm{c}$.

9. Лукьянова Е.Г. 2003. Теория процессуального права. Москва, Норма, 233 с.

10. Лазарев В.В. 1975. Эффективность правоприменительных актов (Вопросы теории). Казань, Изд-во Казан. ун-та, 207 с.

11. Гиниятуллина Л.Н. 2006. Учредительный юридический процесс в представительном органе муниципального образования: по материалам Республики Татарстан: диссертация ... кандидата юридических наук: 12.00.02. Казань, 204 с.

12. Куксин И.С. 2008. Роль юридического процесса в правоприменительной деятельности. Вестник Омского университета. Серия Право, 4 (17): 104-109.

13. Чулюкин Л.Д., Гурьянова В.В. 2018. Сущность и виды правоприменительного юридического процесса. Вестник экономики, права и социологии, 3: 125.

\section{References}

1. Voplenko N.N. 2009. Ocherki obshchej teorii prava [Essays on the general theory of law]. Volgograd, Volgograd State University Publishing House. 898 p.

2. Pavlushina A.A. 2005. Teoriya yuridicheskogo processa: itogi, problemy, perspektivy razvitiya [Theory of legal process: results, problems, prospects of development]. Ed. V.M. Vedyahina. Samara, Samara State Academy of Economics, 480 p.

3. Gorshenev V.M. 1979. O raznovidnostyah yuridicheskogo processa [About the varieties of the legal process]. In: Actual problems of the legal process in the national state: interuniversity thematic collection. Ed. V.M. Gorsheneva. YAroslavl', Yaroslavl State University: 3-10.

4. Polyanskij N.N., Strogovich M.S., Savickij V.M., Mel'nikov A.A. 1983. Problemy sudebnogo prava [Problems of judicial law]. Ed. V. M. Savickogo. M., Publ. Nauka, 223 p.

5. Alekseev S.S. 1971. Social'naya cennost' prava v sovetskom obshchestve [The social value of law in Soviet society]. M., Publ. YUrid. lit., 221 p.

6. Benedik I.V., Gorshenev V.M., Krupin V.G., Mel'nikov Yu.I., Oleinikov S.N., Pogrebnoi I.M., Shakhov I.B. 1985. Teoriya yuridicheskogo processa [Legal process theory]. Kharkiv, Vishcha shk., Publishing house at Kharkiv. Un-te, 192 p. 
7. Gadyl'shina Z.I. 2003. O nekotoryh aktual'nyh problemah administrativno-processual'nogo prava [About some actual problems of administrative procedural law]. In: Actual problems of legal science and education at the present stage. Materials of the scientific and practical conference dedicated to the 50th anniversary of the restoration of the Faculty of Law at Kazan State University (Kazan, October 30-31, 2002). Kazan, Kazan Publishing House: 118-124.

8. Belyaev V.P., Sorokina V.V. 2011. Processual'naya forma yuridicheskoj deyatel'nosti: voprosy teorii i praktiki [Procedural form of legal activity: issues of theory and practice]. M., Publ. YUrlitinform, $144 \mathrm{p}$.

9. Luk'yanova E.G. 2003. Teoriya processual'nogo prava [Theory of procedural law]. M., Publ. Norma, $233 \mathrm{p}$.

10. Lazarev V.V. 1975. Effektivnost' pravoprimenitel'nyh aktov (Voprosy teorii) [Effectiveness of law enforcement acts (Theory issues)]. Kazan, Kazan Publishing House, 207 p.

11. Giniyatullina L.N. 2006. Uchreditel'nyj yuridicheskij process v predstavitel'nom organe municipal'nogo obrazovaniya: po materialam Respubliki Tatarstan [The constituent legal process in the representative body of the municipality: based on the materials of the Republic of Tatarstan]: dissertation ... Candidate of Legal Sciences: 12.00.02. Kazan, 204 p.

12. Kuksin I.S. 2008. Rol' yuridicheskogo processa v pravoprimenitel'noj deyatel'nosti. [The role of the legal process in law enforcement]. Bulletin of Omsk University. Series "Law", 4 (17): 104-109.

13. CHulyukin L.D., Gur'yanova V.V. 2018. Sushchnost' i vidy pravoprimenitel'nogo yuridicheskogo processa. [The essence and types of law enforcement legal process]. Bulletin of Economics, Law and Sociology, 3: 125.

Конфликт интересов: о потенциальном конфликте интересов не сообщалось.

Conflict of interest: no potential conflict of interest related to this article was reported.

\section{ИНФОРМАЦИЯ ОБ АВТОРАХ}

Хабиева Заира Докуевна, старший преподаватель кафедры гражданского права и процесса Чеченского государственного университета имени А.А. Кадырова, г. Грозный, Россия

Ярычев Насруди Увайсович, доктор педагогических наук, профессор кафедры теории и истории государства и права Чеченского государственного университета имени А.А. Кадырова, г. Грозный, Россия

\section{INFORMATION ABOUT THE AUTHORS}

Zaira D. Khabieva, Senior Lecturer of the Department of Civil Law and Procedure of the Kadyrov Chechen State University, Grozny, Russia

Nasrudi U. Yarychev, Doctor of Pedagogical Sciences, Professor of the Department of Theory and History of State and Law of the Kadyrov Chechen State University, Grozny, Russia 